\title{
INSTITUTOS FEDERAIS DE EDUCAÇÃO, CIÊNCIA E TECNOLOGIA: LIMITES E POSSIBILIDADES
}

\author{
Eliezer Moreira Pacheco* \\ Luiz Augusto Caldas Pereira** \\ Moisés Domingos Sobrinho***
}

\section{Resumo}

Os Institutos Federais de Educação, Ciência e Tecnologia criados pela Lei $\mathrm{n}^{\mathrm{o}}$ 11.892, em 29 de dezembro de 2008, representam a nova face da Educação Profissional e Tecnológica brasileira. Neste artigo, são analisados alguns elementos do contexto histórico e político de sua criação, assim como os aspectos mais relevantes e considerados estruturantes dessa nova instituição do campo educacional brasileiro, tais como o seu lugar nas políticas públicas do governo Lula, a sua relação com o mundo produtivo e do trabalho, a sua contribuição para o fortalecimento da democracia e da cidadania, para o desenvolvimento nacional, regional, local, sua proposta curricular e a relação ensino-ciência-tecnologia.

Palavras-chave: Educação Tecnológica. Ciência. Tecnologia. Formação Profissional. Institutos Federais.

\section{Introdução}

O ano de 2009 começou produzindo um evento de grande impacto para a Educação Profissional e Tecnológica (doravante aqui referenciada pela sigla EPT), que foi a transformação dos Centros Federais de Educação Tecnológica (CEFETs), Escolas Técnicas e Agrotécnicas Federais (ETFs e EAFs) e Escolas

\footnotetext{
* Mestre em História, ex-presidente do Inep/MEC e atual Secretário de Educação Profissional e Tecnológica do MEC (eliezer.pacheco@mec.gov.br).

** Mestre em Planejamento e Gestão de Cidades, ex-diretor do Cefet Campos e atual diretor de Políticas para a Educação Profissional e Tecnológica da Setec/MEC (luiz.caldas@mec.gov.br).

*** Doutor em Sociologia, professor da Pós-Graduação em Educação da UFRN. Atuou como coordenador-geral de Estatísticas Especiais do Inep/MEC, coordenador-geral de Desenvolvimento e Modernização e diretor de Programas Especiais da Setec/MEC e Pró-Reitor de Pesquisa e Pós-Graduação do Instituto Federal de Brasília (moises-sobrinho@uol.com.br).
} 
Técnicas Vinculadas à Universidades Federais em Institutos Federais de Educação, Ciência e Tecnologia. Para muitos profissionais e gestores dessa modalidade da educação, já se convencionou nomear as novas instituições apenas como Institutos Federais. No ano em que se iniciaram as comemorações relativas ao centenário da Rede Federal de EPT (as quais devem prosseguir até setembro de 2010), a criação dos institutos, dado o seu caráter inovador e ousado, tem tudo para marcar a história da EPT no país. Neste artigo, serão analisados os aspectos considerados pelos autores como de maior relevância para a consolidação dessas instituições e, quiçá, para a construção de um modelo de Educação Profissional e Tecnológica a ser seguido por outros países com realidades e problemas de desenvolvimento semelhantes aos do Brasil, após, certamente, feitas as adaptações necessárias. Devido às limitações de espaço, deixamos de abordar outros aspectos igualmente importantes para a consolidação dos Institutos, tais como a relação que os mesmos deverão estabelecer com a educação básica do território onde estão inseridos, particularmente na formação de docentes para atender à grande demanda nacional nas áreas de Química, Física, Matemática e Biologia; seu papel no fortalecimento do Programa Nacional de Integração da EPT com a Educação de Jovens e Adultos (Proeja), na extensão tecnológica, envolvendo o apoio às pequenas e médias empresas, cooperativas e organizações sociais sem fins lucrativos, desenvolvimento de inovações educacionais, sociais e organizacionais, dentre outros.

\section{Alguns aspectos do contexto político de criação dos Institutos Federais}

Antes de passarmos à análise dos aspectos escolhidos, façamos algumas considerações sobre o contexto político de surgimento dessas instituições. Comecemos pelo papel estratégico que vem assumindo essa modalidade da educação no atual governo.

\subsection{0 papel estratégico da EPT para o governo Lula}

A ideia da criação dessas novas instituições surgiu no bojo do segundo mandato do presidente Lula, o qual, dentre outros aspectos, será marcado pela determinação do presidente em assegurar à educação e, particularmente, à educação tecnológica um lugar privilegiado nas políticas do seu governo. No caso da EPT, vale lembrar que, para assegurar a atual expansão e modernização, foi necessário um forte esforço político visando revogar o aparato legal responsável por impedir a sua ampliação por todo o país. Como menciona Manfredi (2002), a reforma da Educação Profissional, ocorrida em 1997,

legitimou um dos projetos que estavam em discussão na sociedade civil, 
tendo sido regulamentada pelo Decreto n ${ }^{\circ} 2.208 / 97$, Medida Provisória $n^{\circ}$ 1.549/97 e Portaria $n^{\circ}$ 646/97. Segundo a autora, a reforma legitimou um projeto não consensual, provocando, por um lado, "o dissenso quanto à sua implementação e, por outro, a desestruturação das redes de ensino preexistentes" (p. 294). A Medida Provisória no 1.549/97 (BRASIL, 1997a), por exemplo, em seu artigo 44, apontava para a transferência de responsabilidade de manutenção e gestão do ensino técnico para os Estados, os Municípios e o Distrito Federal, "para o setor produtivo e/ ou para organizações não-governamentais, eximindo a União da responsabilidade de continuar participando da expansão da rede técnica federal" (MANFREDI, 2002). Portanto, somente após a derrubada desses óbices legais, pôde-se pôr em prática a visão estratégica encampada pelo atual governo.

Em 2005, o presidente Lula anunciou o Plano de Expansão da Rede Federal de Educação Profissional e Tecnológica, o qual incluía a construção de 65 unidades de ensino. Com o lançamento do Plano de Desenvolvimento da Educação (PDE) do MEC, em 2007, a expansão passou a fazer parte das ações dele, e o governo anunciou então a construção, até 2009, de mais 150 unidades de ensino, contemplando todos os Estados e o Distrito Federal. Divulgou-se, naquele momento, que seriam investidos $\mathrm{R} \$ 750$ milhões para obras e $\mathrm{R} \$ 500$ milhões, por ano, para custeio e salários de professores e funcionários a serem contratados por meio de concurso público. Considerando-se a primeira e a segunda fase dessa expansão, seriam acrescidas, às 160 mil vagas hoje ofertadas, mais 274 mil vagas, um incremento, portanto, de $171 \%$. A meta é, no entanto, conforme anunciado, chegar até 2010 com algo em torno de $500 \mathrm{mil}$ vagas em todo o território nacional. Se, de 1909 a 2002, o número de escolas destinadas a essa modalidade da educação não ultrapassou 140 unidades, até 2010 a meta é chegar a 354 unidades.

Um aspecto importante, pois inovador, a ser destacado na execução desse Plano de Expansão foi a priorização de critérios técnicos, em detrimento de critérios políticos (diga-se clientelísticos), como tem sido comum na gestão das políticas públicas, para a definição das áreas geográficas e municípios onde deveriam ser instaladas as novas unidades. Por ter a expansão objetivos bem definidos quanto à elevação da oferta de matrículas, interiorização da rede, criação de instituições em Estados e Municípios antes não beneficiados, a metodologia utilizada teve de se pautar, portanto, pelo respeito a análises, dados estatísticos e outros de instituições credenciadas, como o IBGE, Ipea, Inep, MDS, dentre outras, que pudessem contribuir para identificar as mesorregiões e cidades-polo necessárias à sua concretização.

Ao romper com o projeto do governo Fernando Henrique Cardoso para a Educação Profissional e Tecnológica, o governo Lula o fez reconhecendo a 
importância da mesma para um desenvolvimento nacional soberano, sustentável e inclusivo, conforme prega o discurso oficial. Tem sido recorrente, nos discursos divulgados por toda a mídia, o presidente afirmar que não quer ouvir seus assessores falarem em educação como gasto, mas como investimento. Traduzindo a visão predominante no governo sobre o papel da educação, Pacheco (2008, p. 4), atual titular da Secretaria de Educação Profissional e Tecnológica (Setec), afirma:

[...] A educação precisa estar vinculada aos objetivos estratégicos de um projeto que busque não apenas a inclusão nessa sociedade desigual, mas a construção de uma nova sociedade fundada na igualdade política, econômica e social [...]. Quanto à Setec, o conteúdo do nosso trabalho procura afirmar a possibilidade que possui o gestor público de administrar e transformar a educação em um instrumento a serviço da inclusão, da emancipação e da radicalização democrática [...]. Nosso objetivo central não é formar um profissional para o mercado, mas sim um cidadão para o mundo do trabalho, o qual poderia ser tanto um técnico, como um filósofo, um escritor ou tudo isto.

A reflexão sobre essa nova institucionalidade não pode prescindir, portanto, de inseri-la no âmbito de um projeto político que está sendo proposto à sociedade como alternativa de desenvolvimento e construção republicana.

Com base nas linhas gerais traçadas pelo Planalto, essa Secretaria vem, nos últimos três anos, redefinindo as políticas para essa modalidade da educação, como procuraremos mostrar a seguir.

\subsection{As bases da nova política para a Educação Profissional e Tecnológica}

Ao definir as prioridades de atuação da Setec, Pacheco, na obra já citada, destaca ser imperativo observar a relação entre escolarização e profissionalização, visto que existem, no Brasil, cerca de 60 milhões de pessoas com 18 anos ou mais que não conseguiram concluir a educação básica. Na ótica do atual secretário, o conjunto das ações de sua pasta deve, por conseguinte, pautar-se pela indissociabilidade entre formação geral e profissional, na perspectiva da educação integral, e manter uma vinculação orgânica com os arranjos produtivos, sociais e culturais das diferentes regiões brasileiras, visando à inclusão de milhares de mulheres e homens deixados à margem da sociedade brasileira, seja no que tange à escolaridade, seja na perspectiva de sua inserção no mundo do trabalho.

Um dos principais eixos de atuação da Setec é primar, pois, pelo fortalecimento do caráter público da EPT, o que demanda, na visão do secretário, uma estreita articulação da educação profissional e tecnológica com as políticas de desenvolvimento nacional, regional e local. Para tanto, torna-se fundamental 
trabalhar com pesquisas e diagnósticos que dêem visibilidade às demandas culturais, econômicas e sociais, tendo em vista subsidiar a adoção de políticas públicas efetivas e a implementação de mecanismos de acompanhamento e avaliação delas. Isto significa pensar o desenvolvimento em duas de suas mais importantes dimensões: uma endógena, que se alimenta das possibilidades locais e faz brotar um olhar motivador e criador de oportunidades para os que estão construindo no dia-a-dia a história da região, e outra exógena, envolvendo o reconhecimento das iniciativas de grande porte presentes em cada região.

Com base nessas preocupações, a Setec vem desenvolvendo várias iniciativas, como a de construção do Observatório Nacional da Educação Profissional e Tecnológica e do Mundo do Trabalho, cuja principal função será contribuir para a formulação de políticas a partir do diagnóstico e demandas regionais e locais, o qual, por sua vez, integra as ações em curso para o desenvolvimento de um sistema de informações da EPT. Este, uma vez concluído, disponibilizará à consulta pública um conjunto de indicadores educacionais com vistas a assegurar a transparência e o aperfeiçoamento da gestão acadêmica da Rede Federal de Educação Profissional e Tecnológica.

Um dos grandes desafios dessa nova perspectiva para a EPT é construir uma visão da formação profissional e do trabalho que ultrapasse o sentido da subordinação às restritas necessidades do mercado, contribua para o fortalecimento da cidadania dos trabalhadores e democratização do conhecimento em todos os campos e formas. Por essa razão, considera-se fundamental a articulação das políticas de EPT com os programas de trabalho, emprego, renda, inclusão e desenvolvimento social, devendo as primeiras agir como indutoras de emancipação, enquanto as últimas devem ter caráter provisório.

A operacionalização dessa nova visão estratégica exige que a EPT seja fortalecida em todos os níveis e formas, objetivando alcançar, de modo isonômico, os diversos segmentos sociais, sobretudo aqueles historicamente situados à margem das ofertas educativas. Esse fortalecimento, como enfatiza Pacheco (2008), passa pela democratização da oferta da EPT, pela adoção de políticas diferenciadas no sentido de assegurar o acesso e a permanência e pela manutenção da qualidade do ensino ofertado, o que implica, necessariamente, a ampliação da rede pública de educação profissional, como vem acontecendo em todo o País. 


\section{Institutos Federais: antecedentes}

Ao sancionar a Lei $\mathrm{n}^{\circ} 11.892$ (BRASIL, 2008), o presidente Lula encerrou um período de muitas expectativas e debates em torno do que viria a ser um Instituto Federal. Melhor dizendo, fez essas expectativas e debates passarem para outro patamar. Debates que se iniciaram com a edição do Decreto $\mathrm{n}^{\circ}$ 6.095 (BRASIL, 1997b), pelo ministro da Educação Fernando Haddad, e intensamente travados no âmbito da Setec, do Conselho de dirigentes dos Centros Federais de Educação (Concefet), com o próprio ministro e representantes da Rede Federal de EPT, na Câmara de Deputados e em vários outros fóruns e eventos da Rede.

Tendo em vista que o processo de gestação dos Institutos ganhou visibilidade social, a partir da edição de um decreto ministerial, "uma babel de reações semânticas, ideológicas, políticas e outras, típica dos processos de construção psicossocial, quando uma novidade se insere em determinado universo simbólico" (DOMINGOS SOBRINHO, 2008, p. 1) instalou-se no interior da Rede, pois, antes do Decreto, a discussão dizia respeito à transformação dos Cefets, ou de alguns deles, em Universidades Tecnológicas.

Ressalte-se, a esse respeito, o Seminário Nacional, Cefet e Universidade Tecnológica: identidades e modelos, realizado em outubro de 2005, organizado pelos Centros Federais de Educação Tecnológica do Rio de Janeiro, Minas Gerais e Paraná e apoiado pela Setec/MEC, Unesco-Unevoc e Unesco-Brasil. Na Apresentação dos Anais desse evento, afirma-se:

No Brasil, após a aprovação da atual Lei de Diretrizes e Bases da Educação Nacional, em 1966, novas formas de tratamento da Educação no âmbito do currículo e da gestão escolar foram introduzidas no cenário educacional. Entre essas, situa-se a previsão de universidades especializadas por campo de saber, cujo exemplo mais evidente no setor público federal se deu pela recente transformação do Centro Federal de Educação Tecnológica do Paraná em Universidade Tecnológica (SANTOS et al., 2006, p.).

Acreditava-se, pois, que a transformação dos Cefets em instituições universitárias contribuiria decisivamente para o desenvolvimento do País e abriria as portas para um diálogo com outros países, conforme se afirma nos Anais. Por essa razão, participaram do Seminário representantes da Université de Technologie de Compiègne (França), da Fachhochschulen Munchen (Alemanha) e da Association of Canadien Community Colleges - ACCC (Canadá).

Importante ainda sublinhar, dentro do espírito deste breve resgate histórico, o registro feito na seção de encerramento desse evento, com relação a certas reações negativas, devido ao fato de se atribuir o estatuto de universidade aos Cefets: 
[...] a universidade Tecnológica - UT é importante para o País e o preconceito a respeito (grifo nosso) deve ser quebrado com a construção de um modelo que atenda às necessidades sociais. Não adianta a transformação de um Centro Federal de Educação Tecnológica - CEFET em UT e a instituição permanecer com a mesma estrutura curricular, de organização e de gestão anterior (SANTOS et al., 2006, p. 68).

Registre-se, também, a realização em junho de 2005, de um seminário promovido pela Seção Sindical dos Docentes do Cefet - PR , o Sindocefet - PR, com o tema Universidade Tecnológica: concepção e construção, quando ainda tramitava no Senado Federal o Projeto de Lei que criou a Universidade Tecnológica do Paraná (BRASIL, 2004). No texto de mobilização para esse evento, a Seção Sindical anunciava que era necessário envolver os servidores técnicoadministrativos e o corpo discente do Cefet - PR no processo de criação da nova instituição, visando assegurar a mais ampla e democrática participação possível (LIMA FILHO; TAVARES, 2006). Essa preocupação com o debate democrático amparava-se nas inquietações do sindicato relativas às transformações sofridas pela educação tecnológica durante o governo do presidente Fernando Henrique Cardoso, as quais haviam promovido a separação da educação técnica do ensino médio, a extinção dos cursos técnicos integrados, a criação e priorização dos Cursos Superiores de Tecnologia, a transformação das Escolas Técnicas em Centros de Educação Tecnológica, dentre outras mudanças no âmbito da educação em geral, conforme citam os autores acima referenciados.

A referência a esses dois eventos, tomados aqui como os de maior visibilidade, pois houve outros, leva-nos a considerar dois momentos distintos do debate sobre a reconfiguração institucional dos Cefets até a sanção da Lei ${ }^{\circ}$ 11.892, pelo presidente Lula. O primeiro teve início com a criação da Universidade Tecnológica Federal do Paraná (UTFPR), e o segundo com a edição do Decreto do Ministro da Educação.

Se, no primeiro momento dos debates, a nova configuração institucional fazia referência a uma entidade já conhecida, ou seja, a universidade, detentora de ampla legitimidade e sólido status social, no segundo momento, a referência voltava-se para uma entidade não tão amplamente conhecida, um Instituto, e portadora de um status social menor, segundo as visões correntes. Afinal, o que seria um Instituto Federal? Essa a questão dominante após a edição do Decreto.

Por essa razão, a figura do Instituto passou a se constituir, do ponto de vista representacional, numa estranha novidade. Se a representação social (o sentido coletivo) da instituição universitária e a configuração jurídica da mesma são 
sentidos "palpáveis" para a sociedade e a rede, em particular, porque produtos de uma construção histórica, o sentido social do Instituto inexiste e a sua configuração jurídica é algo por construir. Daí a sensação de "estranhamento" presente ainda hoje em muitas discussões sobre o assunto, pois, do ponto de vista perceptivo, representacional, o desconhecido sempre assusta, como bem demonstrou o psicólogo social Serge Moscovici (1967), na sua obra fundadora (DOMINGOS SOBRINHO, p. 3).

Ante a novidade e a ausência de parâmetros para referenciá-la, os diferentes segmentos da Rede lançaram mão de seus próprios referentes culturais e vários discursos passaram então a ganhar espaço nas interações cotidianas. Várias e diversificadas foram essas reações à proposta do ministro. Umas demonstraram completa incompreensão do que se estava propondo; outras manifestaram receio, mas exibiram certa simpatia pela idéia; outras ainda vislumbraram, de imediato, alguma trama do capital internacional e a volta do autoritarismo dos "anos de chumbo". Esse quadro, todavia, se modificou com o passar do tempo, graças, inclusive, à disposição demonstrada pelo ministro para o estabelecimento de um amplo diálogo com a Rede. Desse diálogo e negociações resultou o formato institucional descrito na lei sancionada pelo presidente da República.

\section{Elementos demarcadores e desafiadores para a nova institucionalidade}

Até o início do ano 2009, apenas dois textos oficiais tratavam da configuração institucional da nova realidade: o texto da Lei $\mathrm{n}^{\mathrm{o}} 11.892$, publicado no Diário Oficial da União, em 30 de dezembro de 2008, e o documento da Setec, Concepções e Diretrizes - Instituto Federal de Educação, Ciência e Tecnologia (Cf. Referências). Nesta seção, passaremos a refletir sobre o que consideramos mais desafiador e estruturante para uma instituição cujos idealizadores pretendem transformá-la num marco não só nacional, mas também regional, no âmbito do Mercosul - e, talvez, para outros países com desafios semelhantes aos do Brasil, quanto ao seu desenvolvimento. Comecemos, pois, pelo texto da lei.

Segundo o texto da Lei, no seu art $2^{\circ}$,

Os Institutos Federais são instituições de educação superior, básica e profissional, pluricurriculares e multicampi, especializadas na oferta de educação profissional e tecnológica nas diferentes modalidades de ensino, com base na conjugação de conhecimento técnicos e tecnológicos com as suas práticas pedagógicas, nos termos desta Lei (BRASIL, 2008a).

Para efeitos de regulação, avaliação e supervisão das instituições e dos cursos de educação superior ofertados, os Institutos são equiparados às 
universidades federais. Assim, o seu gestor máximo será um reitor, e cada uma das antigas Unidades Descentralizadas dos Cefets receberá a denominação de campus, tal como ocorre com a instituição que lhe serve de parâmetro. Os gestores dos campi serão chamados, como acontecia com as direções dos antigos Cefets, Diretores-Gerais.

Diz, ainda, o art. $2^{\circ}, \S 3^{\circ}$ :

Os Institutos Federais terão autonomia para criar e extinguir cursos, nos limites de sua área de atuação territorial, bem como para registrar diplomas dos cursos por eles oferecidos, mediante autorização do seu Conselho Superior, aplicando-se, no caso da oferta de cursos a distância, a legislação específica (BRASIL, 2008a).

Dessa forma, a lei pôs fim, pelo menos do ponto de vista legal, a algumas das tensões identitárias e semânticas suscitadas pela nova institucionalidade. Os Institutos nascem, assim, pelo menos no seu formato jurídico-institucional, procurando distinguir-se da universidade clássica (embora nela se inspirem), assumindo uma forma híbrida entre Universidade e Cefet e representando, por isso mesmo, uma desafiadora novidade para a educação brasileira. São instituições de educação superior, mas também de educação básica, e, principalmente, profissional, pluricurriculares e multicampi; terão na formação profissional, nas práticas científicas e tecnológicas e na inserção territorial os principais aspectos definidores de sua existência. Traços que as aproximam e, ao mesmo tempo, as distanciam das universidades. Vejamos com mais detalhes as particularidades distintivas desse novo ente educacional, tomando como base o texto da lei e, com destaque, o documento da Setec, Concepções e Diretrizes (BRASIL, 2008b), o qual aponta, na visão oficial, os principais elementos demarcadores dessa nova institucionalidade. Podemos, dessa forma, fazer algumas reflexões sobre um discurso político amparado por determinada correlação de forças (a conjuntura do governo Lula) e, ao mesmo tempo, sobre as possibilidades que se abrem para a ocorrência de transformações estruturais na educação profissional e na sua relação com a ciência e a tecnologia no País.

\subsection{Os Institutos como política pública}

O documento da Setec ampara-se, de forma coerente, nos princípios norteadores da nova política nacional para a EPT, conforme explicitado na abertura deste texto. Nele, defende-se uma visão de EPT e de suas novas instituições como um bem público, portanto, devendo ser essas pensadas "em função da sociedade como um todo na perspectiva de sua transformação", enquanto aspecto que "funda a igualdade na diversidade (social, econômica, 
geográfica e cultural)" e procurando articular-se com as políticas voltadas para o trabalho e renda, o desenvolvimento setorial, ambiental, social, dentre outros (BRASIL, 2008b, p. 22). Nesse sentido, busca-se romper com uma visão meramente instrumental da mesma, por colocá-la sempre a serviço da acumulação capitalista, e procura-se abrir espaço para um movimento interno que vislumbra no trabalho educativo "importante instrumento de política social, assumida como aquela voltada para a criação de oportunidades, para a redistribuição dos benefícios sociais, visando à diminuição das desigualdades (BRASIL, 2008 b, p. 23). Essa visão política da EPT remete-nos ao segundo elemento.

\subsection{Da relação dos Institutos com o desenvolvimento local e regional}

Para atingir o objetivo político de combate às desigualdades regionais e contribuir na construção de um projeto de nação mais igualitária, segundo prega o discurso oficial, os Institutos precisam estabelecer uma estreita relação com o território onde se situam: "A interferência no local propicia alteração na esfera maior", como diz o documento. Isto significa ir além da compreensão da EPT como instrumentalizadora de pessoas para o trabalho, visando atender exclusivamente aos interesses do mercado. Nessa ótica, torna-se imprescindível situar os Institutos como potencializadores de uma educação capaz de gerar conhecimentos a partir de práticas interativas com a realidade, de modo a propiciar a construção de projetos locais. Isso implica assumir uma postura de combate a todas as formas de autoritarismo na implantação e implementação desses projetos e a defesa da crença de que, ao entrar em contato com a cultura de um determinado território, essa pode se alterar em consequência da interação estabelecida entre os diversos atores e agentes envolvidos (BRASIL, 2008b, p. 25).

\subsection{Do desenho curricular das novas instituições}

Nas orientações para a construção da proposta curricular dos Institutos, o documento propõe um formato capaz, a nosso ver, de efetivar-se como uma forte distinção ante as práticas tradicionais de ensino, seja da educação básica em todo o País, seja em relação à universidade.

Como princípio em sua proposta político-pedagógica, os Institutos Federais deverão ofertar educação básica, principalmente em cursos de ensino médio integrado à educação profissional técnica de nível médio; ensino técnico em geral; cursos superiores de tecnologia, licenciatura e bacharelado em áreas em que a ciência e a tecnologia são componentes determinantes, em particular as engenharias, bem como programas de pós-graduação lato e stricto sensu, sem deixar de assegurar a formação inicial e continuada do trabalhador e dos futuros trabalhadores (BRASIL, 2008b, p. 27). 
Outro diferencial é proposto por meio da verticalização do ensino, devendo essa traduzir-se na oferta:

[...] de diferentes níveis e modalidades da educação profissional e tecnológica, tomando para si a responsabilidade de possibilidades diversas de escolarização como forma de efetivar o seu compromisso com todos (BRASIL, 2008b, p. 27).

Dado esse grau de abrangência, será possível estabelecer uma singularidade na arquitetura curricular dos Institutos, através da "flexibilidade para instituir itinerários de formação" e a "integração dos diferentes níveis da educação básica e do ensino superior", além de criar possibilidades para a educação continuada, buscando atender às demandas da realidade produtiva de cada local ou região (BRASIL, 2008b, p. 28).

O texto assume posição clara contra uma visão disciplinar e fragmentada da ciência e considera ser o espaço dos Institutos propício à oferta de uma formação múltipla e de construção de uma ambiência onde "as multifacetas do processo educativo se evidenciam e trazem a possibilidade de se estabelecerem (sic) nexos internos e promover a inter-relação de saberes" (BRASIL, 2008b, p. 28).

Acredita-se na viabilização dessa arquitetura curricular, visto que os profissionais dessas novas entidades desfrutam da possibilidade de dialogar simultaneamente, e de forma articulada, "da educação básica à pós-graduação, trazendo a formação profissional como paradigma nuclear" (BRASIL, 2008b, p. 28), permitindo, assim, sedimentar o princípio da verticalização do ensino, conforme mencionado acima. Esses profissionais, diferentemente da realidade de outros espaços educativos formais,

[...] têm a possibilidade de, no mesmo espaço institucional, construir vínculos em diferentes níveis e modalidades de ensino, em diferentes níveis da formação profissional, buscar metodologias que melhor se apliquem a cada ação, estabelecendo a indissociabilidade entre ensino, pesquisa e extensão (BRASIL, 2008b, p. 28).

Ora, é evidente que esse modelo curricular exige mudanças no perfil do profissional docente inserido na Rede, pois lidar com o conhecimento de forma integrada e verticalizada exige a superação do "modelo hegemônico disciplinar" e a construção do perfil de um profissional docente capaz de "desenvolver um trabalho reflexivo e criativo e promover transposições didáticas contextualizadas que permitam a construção da autonomia dos educandos" (BRASIL, 2008b, p. 28).

A reflexão sobre essa proposta de desenho curricular remete-nos, necessariamente, à outra discussão, como faremos a seguir. 


\subsection{Da relação entre ciência e tecnologia}

A relação entre ensino, ciência e tecnologia, tendo em vista o mundo do trabalho, deve funcionar, então, como núcleo estruturante dos Institutos. Tomando-se o trabalho como constituinte desse, como diz o documento, propõe-se uma "educação em que o domínio intelectual da tecnologia, a partir da cultura, se firma", em que a formação a ser ofertada tem de necessariamente contemplar "os fundamentos, princípios científicos e linguagens das diversas tecnologias que caracterizam o processo de trabalho contemporâneo" (Setec, 2008, p. 34).

Os Institutos Federais, em sua concepção, amalgamam trabalho-ciênciatecnologia-cultura na busca de soluções para os problemas de seu tempo, aspectos que, necessariamente, devem estar em movimento e articulados ao dinamismo histórico da sociedade em seu processo de desenvolvimento (Setec, 2008, p. 34).

[...] O fazer pedagógico desses Institutos, ao trabalhar na superação ciência/ tecnologia e teoria/ prática, na pesquisa como princípio educativo e científico, nas ações de extensão como forma de diálogo permanente com a sociedade revela sua decisão de romper com um formato consagrado por séculos, de lidar com o conhecimento de forma fragmentada (Setec, 2008, p. 32).

Dois artigos publicados na primeira edição da Revista Brasileira da Educação Profissional e Tecnológica ajudam-nos a refletir sobre esse desafio para os Institutos. O artigo de Moura (2008) aponta a necessidade de a formação e capacitação dos docentes para a EPT ir além da aquisição das técnicas didáticas de transmissão de conteúdos. É preciso ultrapassar os limites de uma educação bancária "na qual o aluno é considerado como depósito passivo de conteúdos transmitidos pelo professor", diz esse autor fazendo referência a Paulo Freire. Nesse processo educativo, o professor precisa assumir outra atitude, forjada a partir de outra informação, "que deve ser crítica, reflexiva e orientada pela responsabilidade social". O docente deve, pois, assumir uma atitude problematizadora e mediadora do processo ensino-aprendizagem, sem, no entanto, "perder sua autoridade nem, tampouco, a responsabilidade com a competência técnica dentro de sua área do conhecimento" (MOURA, 2008, p. 30).

O artigo de Machado (2008) é mais incisivo quando enfatiza que as exigências com relação ao perfil dos docentes são, hoje, bem mais elevadas, porquanto,

Não é mais suficiente o padrão do artesanato, quando o mestre da oficina-escola se apresentava como espelho que o aluno praticamente deveria adotar como referência. Superado também está o padrão da escola-oficina, que impunha ao aluno a aplicação de séries metódicas de aprendizagens. Instrutores recrutados 
nas empresas, segundo o padrão de que para ensinar basta saber fazer, apresentam grandes limitações não somente pedagógicas, mas também teóricas com relação às atividades práticas que ensinam (MACHADO, 2008, p. 15).

Essa modalidade da educação exige nos tempos atuais, por conseguinte, concordam os dois autores, profissionais preparados para enfrentar os novos desafios relacionados às mudanças organizacionais, aos efeitos das inovações tecnológicas sobre as atividades de trabalho e as culturas profissionais, ao aumento das exigências na qualidade da produção e dos serviços - além da preparação para lidar com as implicações éticas de sua intervenção no mundo social, seja no tocante à função social da EPT, seja quanto a suas implicações ecológicas.

Essa discussão sobre a relação ensino-ciência-tecnologia, no contexto do surgimento dos Institutos, merece ser destacada, pois, a nosso ver, está relacionada com as demandas básicas do desenvolvimento nacional, tanto no tocante à formação dos trabalhadores e o fortalecimento de sua cidadania, quanto aos desafios do desenvolvimento da ciência brasileira. Isto porque, por um lado, a Rede Federal de EPT, além de sua missão social, criou condições para assumir um lugar de destaque no desenvolvimento tecnológico nacional, na medida em que o aumento da qualificação do seu quadro de pessoal, a consolidação e ampliação dos seus grupos de pesquisa, a articulação com o mundo econômico, particularmente regional e local, e a forte expansão de suas unidades vem abrindo os espaços necessários à sua consolidação enquanto destacado produtor de pesquisa aplicada e inovações tecnológicas. Por outro lado, embora assumindo o estatuto jurídico de instituição de educação superior, cujo modelo padrão é a universidade, a Rede precisa agora ressaltar/construir os traços que a distinguem dessa.

De sua origem, em 1909, com a criação de uma rede de Escolas de Aprendizes Artífices, que passou, em 1930, a Liceus Industriais, em 1942, a Escolas Técnicas Federais, depois Cefets e hoje Institutos, esse conjunto de instituições federais sempre se modificou em função de demandas oriundas da economia nacional ou de pressões decorrentes dos embates no âmbito do Estado, como foi o caso da reforma de 1997 (CUNHA, 2005). Todavia, mesmo passando por altos e baixos em função de conjunturas, a educação profissional pública federal tornou-se referência para todo o País. Atualmente, com o capital de saberes acumulado e a força simbólica de sua presença no campo educacional, a Rede Federal pode vir a ocupar um novo e importante espaço no desenvolvimento tecnológico nacional, não só por sua excelência na formação de recursos humanos, mas, principalmente, pela possibilidade de aprofundar suas relações com as práticas científico-tecnológicas. Para tanto, impõe-se a 
necessidade de construir demarcações identitárias bem definidas em relação às práticas científicas acadêmicas.

A esse propósito já existe um documento do Fórum Nacional de Dirigentes da Pesquisa e Pós-Graduação (Forpog), que esboça as linhas básicas do lugar que as práticas científico-tecnológicas devem ocupar nos próximos anos.

Constata o documento que os pesquisadores brasileiros, de modo predominante, ocupam cargos acadêmicos, em período integral, seja nas universidades $(74 \%)$, seja em institutos públicos de pesquisa (10\%). Poucos, por conseguinte, trabalham em Pesquisa \& Desenvolvimento no mundo das empresas; se o Brasil é hoje responsável por quase $2 \%$ da publicação mundial de artigos indexados, a produção de patentes é bastante reduzida e quase estacionária; as atividades de pesquisa e pós-graduação estão fortemente concentradas no Sudeste e no Sul. Daí conclui o Forpog:

Uma constatação de extrema importância para os Institutos que salta aos olhos ao se ler esses dados é o descolamento das práticas científicas desenvolvidas no mundo acadêmico das demandas tecnológicas da sociedade. Não obstante a universidade brasileira desempenhe um destacado papel na formação de recursos humanos em alto nível, isso não a tem impedido de distanciar-se do mundo das demandas concretas. Aí parece estar então o maior diferencial das práticas de pesquisa a serem assumidas pela Rede Federal de EPT: o desenvolvimento de pesquisa aplicada e sintonizada com as demandas do desenvolvimento local e regional (FORPOG/CONCEFET, 2008, p. 7).

A posição assumida por esse fórum é bastante esclarecedora quanto às relações que devem se estabelecer entre ensino, ciência e tecnologia nos Institutos. A articulação desses três elementos, se assim vier a se concretizar, pode constituir-se no núcleo duro estruturante da identidade dessas novas instituições e de seus agentes. Ao contrário da "educação bancária" predominante na educação básica do País, cujas consequências são por demais evidentes, quando, por exemplo, os alunos brasileiros participam de avaliações internacionais como o Pisa, e ao contrário das práticas científicas distanciadas dos contextos regionais e locais, a relação ensino/pesquisa pode constituirse num forte diferencial para a nova institucionalidade. Aliás, essa relação já está presente em várias das instituições que foram transformadas em Institutos e na Universidade Tecnológica Federal do Paraná, embora, se tomarmos a rede como um todo, isso aconteça com grandes variações.

As proposições expressas nos dois documentos oficiais aqui citados, assim como os argumentos em defesa da construção de um novo perfil para o docente (e, por que não dizer, para os demais profissionais envolvidos com a EPT) exigem a incorporação de um novo lidar com a ciência no âmbito da 
Rede. Exigem a desmistificação da ciência como algo transcendental, inacessível ao simples mortais, e a superação da crença de que ciência e tecnologia são elementos dissociados. No primeiro caso, como diz Japiassu, se muitos pecados são cometidos em relação à verdade científica "[...] é porque frequentemente é considerada como caída do céu, não tendo raízes terrenas e humanas" (JAPIASSU, 1996, p. 15). No segundo caso, a tecnologia, como diz Bunge (1980, p. 207), não está separada da teoria "nem é mera aplicação da ciência pura: tem uma componente criativa particularmente manifesta na pesquisa tecnológica e no planejamento de políticas tecnológicas".

$\mathrm{O}$ processo ensino-aprendizagem mediado pela pesquisa, segundo essa ótica, deve, em consequência, levar alunos e professores a agir como sujeitos que se debruçam sobre um objeto de investigação buscando compreendê-lo e construir respostas ou modelos explicativos sempre provisórios, a depender do tempo e espaço de suas formulações. A articulação ensino/ ciência/tecnologia e sua vinculação com o mundo do trabalho, todavia, para efetivamente se concretizar, depende também da consolidação, como ressaltamos na abertura deste artigo, do projeto político que está sendo proposto pelo atual governo. Consolidação que exige igualmente a superação de crenças e pregações ideológicas, além de determinada correlação de forças.

\section{Considerações finais}

A criação dos Institutos Federais, como se procurou demonstrar, apresenta limites a serem observados, mas também amplas possibilidades para o desenvolvimento da EPT no Brasil. Sua consolidação dependerá da conjugação de certos fatores, tais como a compreensão, pelos diferentes atores, do papel estratégico que ela pode assumir no desenvolvimento nacional e no fortalecimento da cidadania, e a sua tradução nas práticas cotidianas da Rede, e não apenas no plano retórico; da capacidade de articulação das políticas para a EPT com as demais políticas públicas desenvolvidas pelo atual governo e, a partir do próximo ano, com as políticas dos novos dirigentes nacionais. Sem isso, a Educação Profissional poderá ficar restrita, como em outros momentos de sua história, à formação de trabalhadores para atender às demandas exclusivas do mercado. Acrescentamos ainda: para além das conjunturas políticas da administração federal, é fundamental que se consolide a construção, a nosso ver, de um dos mais importantes diferenciais identitários dos Institutos, qual seja a sua capacidade de articular ensino/ ciência/tecnologia em sintonia com as demandas do desenvolvimento local e regional, o que implicará necessariamente um embate simbólico de significações e ressignificações dos modelos de educação profissional pré-existentes na Rede (Escola 
Agrotécnica, Escola Vinculada, Cefet, Escola Técnica) e na sua diferenciação do modelo acadêmico da relação ensino/ ciência/tecnologia predominante na universidade brasileira, da qual seu corpo docente é originário. A consolidação dos Institutos Federais insere-se, portanto, numa realidade bastante complexa e a construir. Sua efetivação envolverá, necessariamente, disso não se poderá fugir, a disputa de projetos para a sociedade como um todo, não apenas para a EPT.

\section{Referências}

BRASIL. Medida Provisória n ${ }^{\circ} 1.549$, de 14 de março de 1997. Dispõe sobre a organização da Presidência da República e dos Ministérios e dá outras providências. Diário Oficial da União, Brasília, 17 mar. 1997a.

BRASIL. Decreto n ${ }^{\circ} 2.208$, de 17 de abril de 1997. Brasília, DF, 1997. Regulamenta o $\S$ $2^{\circ}$ do art. 36 e os arts. 39 a 42, da Lei n 9.394/96. Diário Oficial da União, Brasília, Edição ${ }^{\circ}$ 74, 18 abr. 1997b.

BRASIL. Ministério da Educação. Portaria n ${ }^{\circ}$ 646/97, de 14 de maio de 1997. Regulamenta a implantação do disposto nos artigos 39 a 42 da Lei $n^{\circ} 9.349$ e do Decreto $n^{\circ}$ 2.208, de 17 de abril de 1997, e dá outras providências. Diário Oficial da República Federativa do Brasil, nº 56, Brasília, 15 mai. 1997c.

BRASIL. Projeto de Lei $n^{\circ} 4.183 / 04$. Transforma o Centro Federal de Educação Tecnológica do Paraná em Universidade Federal Tecnológica do Paraná. Data da apresentação à Câmara dos Deputados: 29/10/04. Brasília, 2004.

BRASIL. Decreto n ${ }^{\circ} 6.095$, de 24 de abril de 2007. Estabelece diretrizes para o processo de integração de instituições federais de educação tecnológica, para fins de constituição dos Institutos Federais de Educação, Ciência e Tecnologia - IFET, no âmbito da Rede Federal de Educação Tecnológica. Diário Oficial da União, Brasília, 25 abr. 2007.

BRASIL. Lei n ${ }^{\circ} 11.892$, de 29 de dezembro de 2008. Institui a Rede Federal de Educação Profissional, Científica e Tecnológica, cria os Institutos Federais de Educação, Ciência e Tecnologia, e dá outras providências. Diário Oficial da União, Brasília, 30 dez. 2008a, Seção 1, p. 1.

BRASIL, Inep / MEC. Universidade e mundo do trabalho. Brasília: Inep/MEC, 2006 (Coleção Educação Superior em debate, v. 3).

BRASIL. MEC/Setec. Concepção e diretrizes - Instituto Federal de Educação, Ciência e Tecnologia. Brasília: MEC/Setec, 2008b.

BUNGE, Mário. Ciência e desenvolvimento. Belo Horizonte: Itatiaia, 1980.

CONSELHO DE DIRIGENTES DOS CENTROS FEDERAIS DE EDUCAÇÃO (CONCEFET). Manifestação do Concefet sobre os Institutos Federais de Educação, Ciência e Tecnologia. Revista Brasileira da Educação Profissional e Tecnológica. Brasília, MEC, Setec, v. 1, n. 1, jun. 2008. 
CUNHA, Luiz Antônio. O ensino profissional na irradiação do industrialismo. São Paulo: Edtora Unesp; Brasília: Flacso, 2005.

DOMINGOS SOBRINHO, Moisés. Universidade Tecnológica ou Instituto Federal de Educação, Ciência e Tecnologia? Disponível em. http: / / portal.mec.gov.br/setec/arquivos / pdf3/artigos. Acesso em: 6 jan. 2009.

FÓRUM NACIONAL DOS DIRIGENTES DA PESQUISA E PÓS-GRADUAÇÃO/ CONCEFET. O lugar da pesquisa, pós-graduação e inovação nos Institutos Federais de Educação, Ciência e Tecnologia. São Luís, XXXII REDITEC, 2008. Disponível em http:/ / portal.mec.gov.br/setec/arquivos/pdf3.

JAPIASSU, Hilton. A crise da razão e do saber objetivo. São Paulo: Letras \& Letras, 1996.

LIMA FILHO, Domingos Leite; TAVARES, Adilson Gil. Universidade Tecnológica - concepções, limites e possibilidades. Curitiba: SINDOCEFET-PR, 2006.

MACHADO, Lucília Regina de Souza. Diferenciais inovadores na formação de professores para a educação profissional. Revista Brasileira da Educação Profissional e Tecnológica. Brasília, MEC, Setec, v. 1, n. 1, p. 8-22, jun. 2008.

MANFREDI, Sílvia Maria. Educação profissional no Brasil. São Paulo: Cortez, 2002.

MOURA, Dante Henrique. A formação de docentes para a educação profissional e tecnológica. Revista Brasileira da Educação Profissional e Tecnológica. Brasília, MEC, Setec, v. 1, n. 1, p. 23-37, jun. 2008.

PACHECO, Eliezer Moreira. Bases para uma Política Nacional de EPT (2008). Disponível em. http:/ / portal.mec.gov.br/ setec/arquivos / pdf3/artigos. Acesso em: 8 jan. 2009. PEREIRA, Luiz Augusto Caldas. Institutos Federais de Educação, Ciência e Tecnologia. Disponível em. http: / / portal.mec.gov.br/ setec/arquivos/pdf3/ artigos. Acesso em: 10 jan. 2009.

SANTOS, Flávio Antônio dos et al. SEMINÁRIO NACIONAL CEFET E UNIVERSIDADE TECNOLÓGICA: IDENTIDADES E MODELOS. Anais. Brasília, DF: CefetMG, 2005. 


\section{Federal Institutes of Education, Science and Technology: limits and possibilities Abstract}

The Federal Institutes of Education, Science and Technology created by the law 11.892, December 29 $9^{\text {th }}, 2008$, represent a new face of the Brazilian Technological and Professional Education. The main objective of this article is to analyze some aspects of the historical and political context of their creation, as well as those more relevant and considering structuring of this new institution within the educational field. These include their place within the public policies of Lula's government, their relations with the working and production world, their contribution to Democracy and citizenship, to national, regional and local development, their proposition of technological education and the relation of teaching, science and technology.

Keywords: Technological education. Science. Technology. Professional training. Federal institutes.

\section{Les Instituts Fédéraux d'Éducation, Science et Technologie : limites et possibilités Résumé}

Les Instituts Fédéraux d'Éducation, Science et Technologie créés par la Loi 11.892 le 29 Décembre 2008, représentent la nouvelle face de l'Éducation Professionnelle et Technologique brésilienne. Dans cet article, seront analysés quelques éléments du contexte historique et politique de la création de ceux-ci, bien comme les aspects plus marquants et considérés structurants de cette nouvelle institution dans le champs éducationnel brésilien. Y sont inclus les aspects relatifs à leur place au sein des politiques publiques du gouvernement Lula et la relation avec le monde du travail et de la production, la contribution envers le renforcement de la Démocratie et de la citoyenneté, pour le développement national, régional et local, leur propostion curriculaire et la relation enseignement-science-technologie.

Mots clefs: Éducation technologique. Science. Technologie. Formation professionnelle. Instituts fédéraux.

\section{Institutos Federales de Educación, Ciencia y Tecnología: límites y posibilidades Resumen}

Los Institutos Federales de Educación, Ciencia y Tecnología creados por la ley n ${ }^{\circ}$ 11.892, en 29 de diciembre de 2008, representan la nueva faz de la educación profesional y tecnológica brasileña. En este artículo, son analizados algunos elementos del contexto histórico y político de su creación, bien como los aspectos más relevantes y considerados estructurantes de esa nueva institución del campo educacional brasileño, tales como su lugar en las políticas públicas del gobierno Lula, su relación con el mundo productivo y del trabajo, su contribución para el fortalecimiento de la democracia y de la ciudadanía, para el desarrollo nacional, regional, local, su propuesta curricular y la relación enseñanza - ciencia - tecnología.

Palabras clave: Educación tecnológica. Tecnología. Formación profesional. Institutos Federales. 